CARDIOVASCULAR MEDICINE

\title{
Testosterone replacement in hypogonadal men with angina improves ischaemic threshold and quality of life
}

\author{
C J Malkin, P J Pugh, P D Morris, K E Kerry, R D Jones, T H Jones, K S Channer
}

Heart 2004;90:871-876. doi: 10.1136/hrt.2003.021121

See end of article for authors' affiliations

......................

Correspondence to:

Dr K S Channer, M131,

Cardiology, Royal

Hallamshire Hospital

Glossop Road, Sheffield

S10 2JF, UK; email:

kevin.channer@sth.nhs.uk

Accepted

13 November 2003

\begin{abstract}
Background: Low serum testosterone is associated with several cardiovascular risk factors including dyslipidaemia, adverse clotting profiles, obesity, and insulin resistance. Testosterone has been reported to improve symptoms of angina and delay time to ischaemic threshold in unselected men with coronary disease.

Objective: This randomised single blind placebo controlled crossover study compared testosterone replacement therapy (Sustanon 100) with placebo in 10 men with ischaemic heart disease and hypogonadism.

Results: Baseline total testosterone and bioavailable testosterone were respectively $4.2(0.5) \mathrm{nmol} / \mathrm{l}$ and $1.7(0.4) \mathrm{nmol} / \mathrm{l}$. After a month of testosterone, delta value analysis between testosterone and placebo phase showed that mean (SD) trough testosterone concentrations increased significantly by 4.8 (6.6) $\mathrm{nmol} / \mathrm{l}$ (total testosterone) $(\mathrm{p}=0.05$ ) and $3.8(4.5) \mathrm{nmol} / \mathrm{I}$ (bioavailable testosterone) ( $p=0.025)$, time to $1 \mathrm{~mm}$ ST segment depression assessed by Bruce protocol exercise treadmill testing increased by $74(54)$ seconds ( $p=0.002)$, and mood scores assessed with validated questionnaires all improved. Compared with placebo, testosterone therapy was also associated with a significant reduction of total cholesterol and serum tumour necrosis factor $\alpha$ with delta values of $-0.41(0.54) \mathrm{mmol} / \mathrm{l}$ $(\mathrm{p}=0.04)$ and $-1.8(2.4) \mathrm{pg} / \mathrm{ml}(\mathrm{p}=0.05)$ respectively.

Conclusion: Testosterone replacement therapy in hypogonadal men delays time to ischaemia, improves mood, and is associated with potentially beneficial reductions of total cholesterol and serum tumour necrosis factor $\alpha$.
\end{abstract}

W orldwide, men are more than three times as likely to develop ischaemic heart disease as women. The cause of this excess pathology is unclear but it is not explained by differences in the classic cardiovascular risk factors. ${ }^{12}$ It was believed that female sex hormones were cardioprotective but two large randomised controlled trials of female hormone replacement have shown that this is not the case. ${ }^{34}$ Similarly, it has been assumed that male sex and by inference male hormones contributed to the excess male risk. Indeed, the British National Formulary advises caution if considering prescription of testosterone therapy to men with known cardiac disease. In contrast, evidence is now emerging that low serum testosterone is associated with many of the classic cardiovascular risk factors. ${ }^{5}$ Two large studies have recently found low testosterone to be associated with increased burden of aortic and carotid atheroma. ${ }^{67}$ Furthermore, our research group has found in cross sectional investigations that men with coronary disease have lower androgen concentrations than men with normal angiograms ${ }^{8}$ and that the overall prevalence of overt biochemical hypogonadism in 830 men with proven coronary artery disease at angiography was $23.4 \%$, which is approximately three times higher than the background healthy community prevalence. $^{10}$

In vitro and in vivo studies have found testosterone to be a coronary vasodilator. ${ }^{11-13}$ A number of research groups have reported that testosterone therapy with intramuscular, ${ }^{14}$ intravenous, ${ }^{15}$ and transdermal preparations had a beneficial anti-ischaemic effect in men with coronary disease. ${ }^{16}$ The populations of men in these studies were randomly chosen and not selected on the basis of endogenous hormone concentrations. Given that testosterone therapy is of benefit to eugonadal men with coronary disease it would be expected that hormone replacement for hypogonadal men would be of even greater benefit. Since a large proportion of men with coronary disease are biochemically hypogonadal this proof of concept would be an important finding.

This study was designed to test whether testosterone therapy improves myocardial ischaemia in hypogonadal men with coronary disease and angina as shown by improvement in time to ischaemic threshold, assessed by treadmill exercise testing.

\section{METHODS}

\section{Summary of protocol}

This was a randomised, single blind crossover study of testosterone replacement therapy versus placebo in men with hypogonadism and coronary heart disease. Men who had never had an exercise test were required to perform a run-in exercise test according to the standard Bruce protocol. Participants were randomly assigned to testosterone injections ( $1 \mathrm{ml}$ of Sustanon 100, $100 \mathrm{mg}$ testosterone/ml) every two weeks or placebo for one month. Drug order was allocated by blocks of computer generated random numbers. Before and after the month of treatment, patients were assessed in the cardiology department with questionnaires, blood tests, and a treadmill exercise test. After the initial month of treatment there was a month washout period of no treatment, after which the patient crossed over to the alternate arm of treatment. At the end of the three month study period, patients continued taking testosterone as prescribed by their own doctor.

Abbreviations: ELISA, enzyme linked immunosorbent assay; HDL, high density lipoprotein; LDL, low density lipoprotein; PSA, prostate specific antigen; TNF $\alpha$, tumour necrosis factor $\alpha$ 


\section{Participants}

Twelve men with coronary artery disease ( $>70 \%$ stenosis of a major coronary artery at coronary angiography) or previous proven myocardial infarction with typical symptoms of angina pectoris were recruited from August 2002 to December 2002. These patients were referred from a male andrology clinic and each had a clinical need for testosterone replacement as judged by a consultant endocrinologist (THJ). All patients were naive to androgen replacement and their androgen status had never been investigated. All patients gave informed written consent and the local ethics committee approved the protocol. No changes were made to antianginal medication for four weeks before or during the trial. Inclusion criteria for patients were male sex, age greater than 18 years, and a clinical indication for testosterone therapy. Patients were excluded if they had a prostate specific antigen (PSA) concentration above the normal range or any other contraindication to androgen therapy. They were also excluded if they had left main stem (or equivalent) stenosis, a coronary or cerebrovascular event or other trial drugs within the preceding three months, severe hypertension (blood pressure $>180 / 114 \mathrm{~mm} \mathrm{Hg}$ ), significant arrhythmia, poor physical mobility, and ECG abnormalities precluding ST segment analysis on a treadmill.

Of 12 patients screened, one patient did not meet accepted ECG criteria during exercise treadmill testing and 11 were randomly assigned to treatment. One study patient underwent an elective coronary artery bypass earlier than expected and was withdrawn from the study. Complete data were available for 10 patients; table 1 presents baseline data.

\section{Drug}

We used intramuscular injection of Sustanon 100 every two weeks, which is the usual method of initiating testosterone treatment in men with hypogonadism. Testosterone (Sustanon 100, $100 \mathrm{mg}$ testosterone/ml; Organon Laboratories Ltd, Cambridge, UK) or placebo ( $1 \mathrm{ml}$ of $0.9 \%$ normal saline) in an identical syringe was given by deep intramuscular injection to the buttock every two weeks by a member of the research staff. Patients were blinded to the identity of the injection and the drug was drawn up away from the patient.

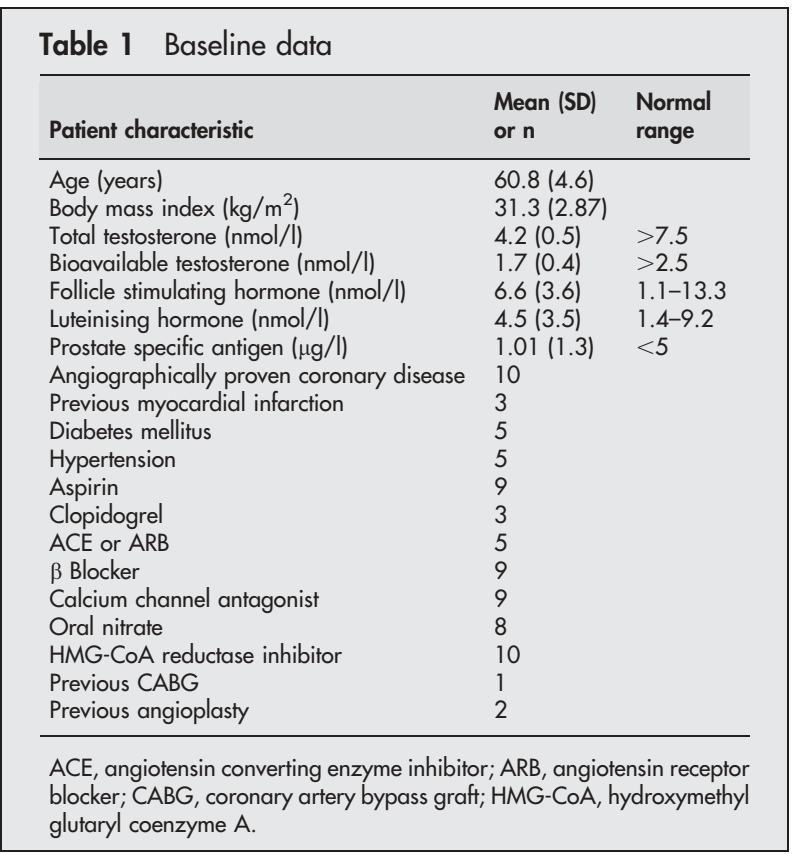

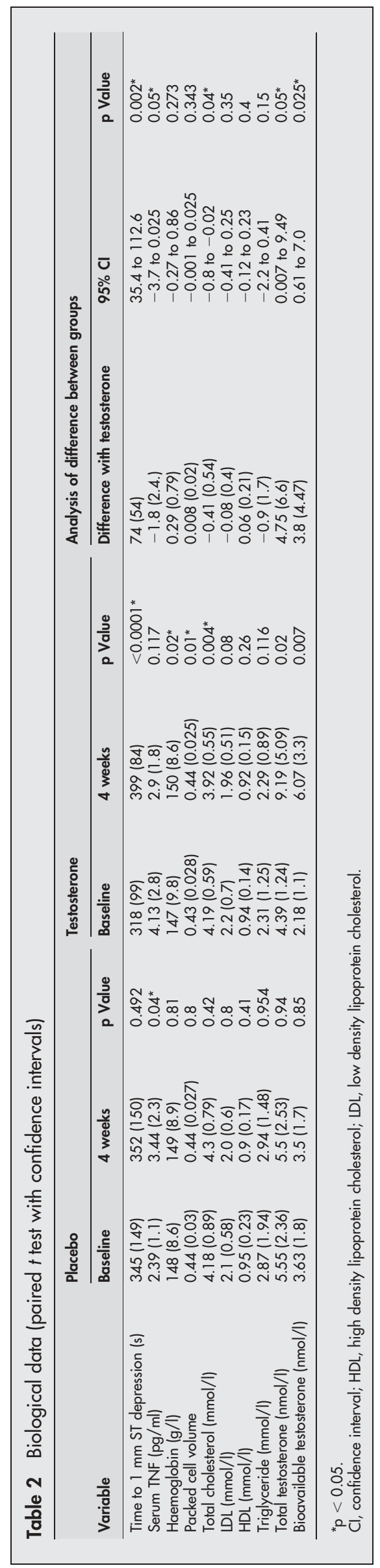




\section{Patient assessment}

Patients were assessed at weeks $0,4,8$, and 12 between 8 am and 9.30 am under fasting conditions and within 10-14 days of the final injection of that phase. Demographic details, hormone profiles, PSA concentration, and antianginal drug use were recorded at the beginning of the trial. Treadmill exercise testing was performed at weeks $0,4,8$, and 12 according to the Bruce protocol (MAX-1 Marquette advanced exercise system, software version 002E). Patients continued their medication but were asked not to use glyceryl trinitrate for six hours before the test. The primary end point was defined as the time to $1 \mathrm{~mm}$ ST segment depression and exercise tests were terminated when this criterion was met. All treadmill tests were supervised by a cardiac technician with one investigator (CJM) present.

Electrocardiographic data were analysed by the Marquette 002E software package. This system analyses the signal averaged ECG and produces a graphical display of the level of the ST segment $80 \mathrm{~ms}$ after the $J$ point against time. Time to $1 \mathrm{~mm}$ ST segment depression was measured from computer derived analysis effectively eliminating observer bias. All blood tests were performed at weeks $0,4,8$, and 12; total testosterone and sex hormone binding globulin were measured by enzyme immunoassay (DRG Instruments GmbH, Marburg, Germany). Bioavailable testosterone was calculated by a modification of the method described by Tremblay and Dube. ${ }^{17}$ In this method testosterone is removed from the test serum by the addition of activated charcoal and replaced by testosterone labelled with hydrogen-3, which binds to sex hormone binding globulin and other plasma proteins in equimolar concentrations as native testosterone. Sex hormone binding globulin-bound testosterone is then precipitated out of the sample by the addition of cold ammonium sulfate. The remaining ${ }^{3} \mathrm{H}$-testosterone, comprising the unbound fraction and the fraction weakly bound to albumen, is then measured by a $\beta$ counter. Full blood count, glucose concentration, and lipid profiles were measured with standard hospital assays. Low density lipoprotein (LDL) cholesterol was calculated with the Friedewald equation $(($ LDL cholesterol $=$ total cholesterol $-($ high density lipoprotein (HDL) cholesterol + triglyceride / 2.2)). Serum tumour necrosis factor $\alpha(\mathrm{TNF} \alpha)$ was assayed with high sensitivity enzyme linked immunosorbent assay (ELISA) (Quantikine R\&D, Abingdon, UK). PSA was measured at the beginning and end of the trial.

Patients were asked to complete the Seattle angina questionnaire (an objective measure of quality of life in patients with angina), the Beck depression inventory (a commonly used assessment of mood and depressive symptoms), the general health screening questionnaire (a multipurpose mood and general wellbeing screening tool), and the androgen deficiency in the adult male screening

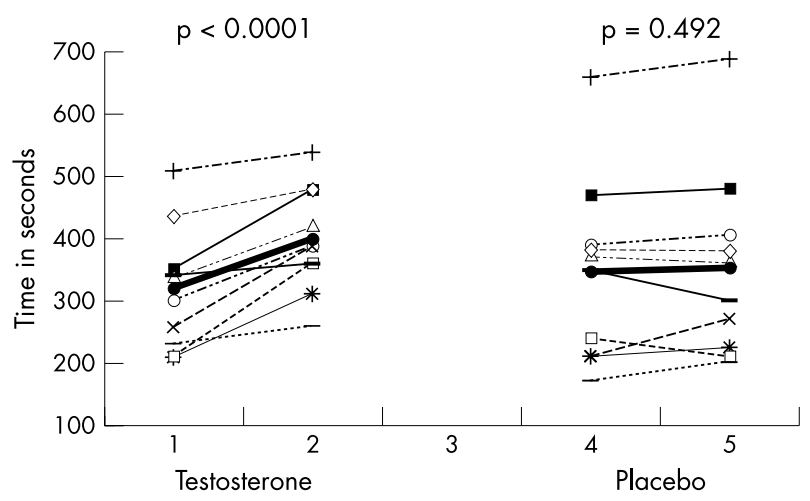

Figure 1 Change in exercise time. Mean is indicated in bold. questionnaire at weeks $0,4,8$, and 12. The androgen screening questionnaire is a 10 statement true or false answer sheet. A positive screen is defined as a score of 3 or more out of 10 or a single positive response to any one of two highly specific questions: "Do you have reduced libido (sex drive)?" or "Do you have reduced ability to maintain erections?"

\section{Statistical analysis and sample size calculation}

From previous work with eugonadal men, in which we found a $37 \%$ increase in time to $1 \mathrm{~mm}$ ST segment depression with testosterone, we calculated that for hypogonadal men 12 participants would be needed to detect a $50 \%$ increase in a crossover study protocol, with $80 \%$ power and $5 \%$ significance.

The raw data were analysed with a statistical software package (SPSS version 11.5, SPSS Inc, Chicago, Illinois, USA). The data were tested against a normal distribution with Kolmogorov-Smirnov tests. All the biological data were found to be normally distributed and therefore were tested with paired $t$ tests. Questionnaire scores were compared by Wilcoxon matched pair tests. The baseline results of each crossover phase were examined and tested for period or treatment period interaction. When no such interaction was found data were deemed suitable for further analysis. Unless otherwise stated, data are expressed as mean (SD). Significance was accepted when $\mathrm{p}<0.05$.

\section{RESULTS}

Ten patients completed the study. Table 2 summarises the results. Testosterone treatment induced a rise in serum testosterone, whereas placebo had no significant effect. The time to $1 \mathrm{~mm}$ ST segment depression increased by 81 (48) seconds in the testosterone phase compared with an increase of 7.2 (32) seconds in the placebo phase (fig 1). The mean difference in exercise time between testosterone therapy and placebo was 74 (54) seconds (95\% confidence interval (CI) 35.4 to 112.6 seconds). Compared with placebo, testosterone therapy also induced small but significant rises in haemoglobin and packed cell volume but reductions in serum TNF $\alpha$ and total cholesterol (fig 2).

As expected serum PSA measured at screening and at the end of the trial rose slightly (from 1.01 (1.3) to 1.10 (1.4) $\mu \mathrm{g} / \mathrm{l}$, $\mathrm{p}=0.03)$; however, there were no new symptoms of prostatic outflow obstruction and the final concentration of PSA remained well within the age adjusted normal range $(<4.5 \mu \mathrm{g} / \mathrm{l})$. No other adverse effects were reported.

Testosterone treatment was also associated with significant improvement in mood, as assessed by questionnaire (table 3). Compared with placebo there were reductions in Beck depression inventory scores, general health screening score, and androgen deficiency screening scores (fig 3). There was a trend to reduction of the Seattle angina questionnaire score, but this did not reach significance.

\section{DISCUSSION \\ Effect on myocardial ischaemia}

In this study we have shown that one month of intramuscular testosterone replacement given to men with low basal testosterone and hypogonadism significantly improved time to ischaemic threshold compared with placebo. The absolute increase in time to ischaemia was about equivalent to half of one stage on a standard Bruce exercise protocol. This finding is in agreement with reports from several centres of an antiischaemic effect of testosterone. ${ }^{14-16}$ The fact that such a significant improvement in exercise time was seen with only one month of treatment suggests a rapid mode of action. Testosterone has been shown in numerous studies to be a vasodilator ${ }^{11-13}$ and we presume this to be the basis of its 


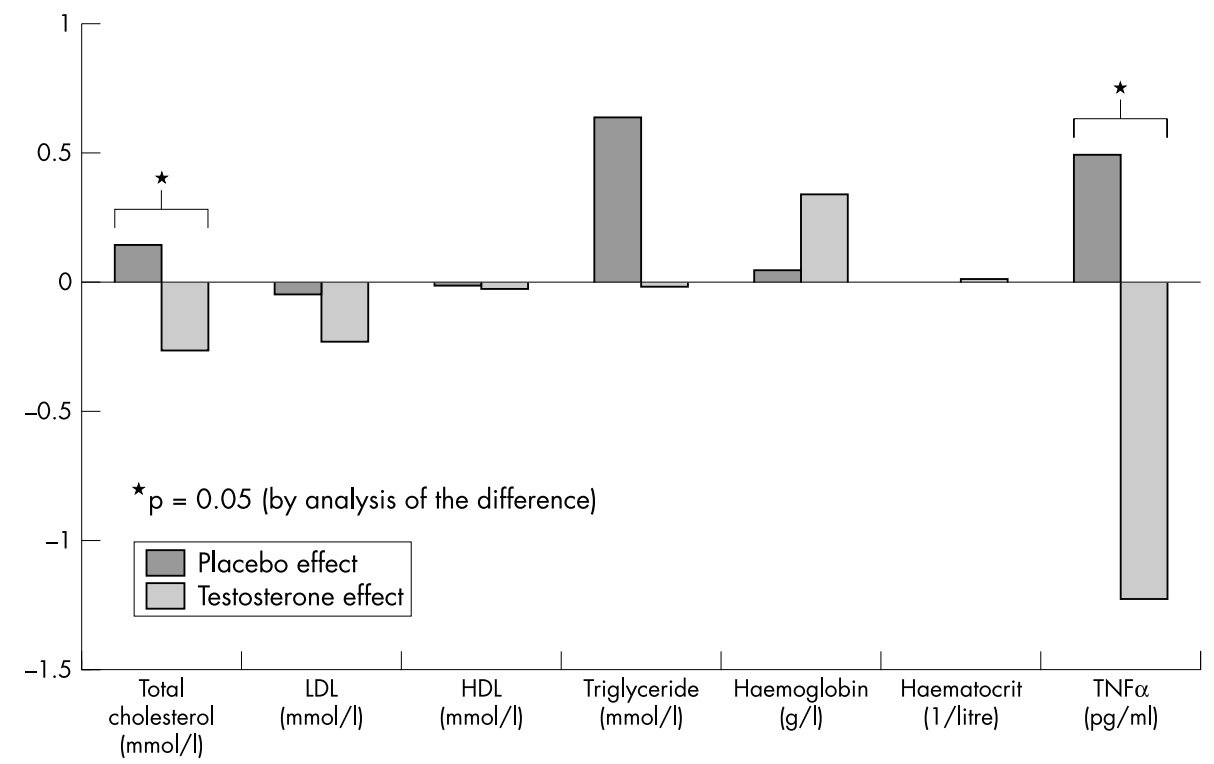

Figure 2 Effect by treatment on serum parameters. HDL, high density ipoprotein cholesterol; LDL, low density lipoprotein cholesterol; $\mathrm{TNF} \alpha$, tumour necrosis factor $\alpha$.

anti-ischaemic action. This is the first study to examine exclusively hypogonadal men, although in our previous study of eugonadal men we did find a significant negative correlation between basal testosterone and increase in ischaemic threshold ${ }^{16}$ The greater benefit seen in this present study of a hypogonadal cohort confirms the dose response effect that we found in our earlier study.

\section{Effect on cholesterol}

Testosterone therapy induced a reduction in serum total cholesterol, with no other significant effects seen on other lipid profiles. The effects of testosterone on lipid profiles are controversial. Most studies report that testosterone therapy causes reductions in HDL cholesterol, ${ }^{18}{ }^{19}$ although this effect is absent or less apparent in elderly, hypogonadal, or obese men. ${ }^{20} 21$ Despite some conflicting data, in most studies testosterone effects modest reductions of total and LDL cholesterol. ${ }^{22-24}$ A recent meta-analysis supported these findings. ${ }^{25}$ We found a similar reduction in total cholesterol in the present study even though all patients were treated with a statin. The reduction in LDL cholesterol was not significant and no reduction was seen in HDL cholesterol, which may be due to effects on insulin sensitivity. Testosterone therapy is reported to improve insulin resistance and components of the metabolic syndrome in obese men ${ }^{26}$ and in men with low testosterone. ${ }^{27}$ Given that in our cohort all were hypogonadal, 50\% were diabetic, and the mean body mass index was $31.3 \mathrm{~kg} / \mathrm{m}^{2}$ it is possible that a positive effect on features of the insulin resistance syndrome attenuated the expected reduction in HDL cholesterol (reviewed in reference 28). In addition, we cannot exclude an interaction with testosterone and the hydroxymethyl glutaryl coenzyme
A reductase inhibitors. In postmenopausal women, for example, the administration of statin and hormone replacement is associated with greater cholesterol reduction than with statin alone..$^{29} 30$

\section{Effects on TNF $\alpha$}

$\mathrm{TNF} \alpha$ is a pro-inflammatory cytokine and is increased in infective and inflammatory diseases. Atherosclerosis is acknowledged to be a disease of chronic inflammation. TNF $\alpha$ is both a marker and a mediator of atherosclerotic plaque development and complications. Serum TNF $\alpha$ is greatly increased during acute coronary syndromes but is also increased to a lesser degree in stable chronic angina and is a marker of future events. ${ }^{31}$ In this study we have shown that testosterone induces a small but significant reduction of $\mathrm{TNF} \alpha$ compared with placebo. This is an intriguing finding, since there is considerable evidence from laboratory and clinical studies that testosterone has immune modulating effects. The reduced frequency of autoimmune disease in men compared with women has been attributed to the antiinflammatory effect of androgens compared with oestrogens. ${ }^{32}$ There are several case reports and randomised controlled trials of androgen therapy in patients with inflammatory disease such as rheumatoid arthritis or systemic lupus erythematosus in which androgens have been found to improve clinical status and reduce inflammatory markers. ${ }^{33-35}$ In cell culture studies testosterone has been found to reduce the expression of pro-inflammatory cytokines such as $\mathrm{TNF} \alpha$, interleukin 1 , and interleukin 6 in human vascular endothelium, monocytes, and fibroblasts. ${ }^{36-39}$ In live mice, gonadectomy and injection of bacterial endotoxin resulted in increased TNF production, which was

Table 3 Questionnaire data (Wilcoxon matched pairs tests)

\begin{tabular}{|c|c|c|c|c|c|c|c|c|}
\hline \multirow[b]{2}{*}{ Questionnaire } & \multicolumn{3}{|l|}{ Placebo } & \multicolumn{3}{|c|}{ Testosterone } & \multicolumn{2}{|c|}{$\begin{array}{l}\text { Analysis of difference with } \\
\text { testosterone }\end{array}$} \\
\hline & Baseline & 4 weeks & p Value & Baseline & 4 weeks & p Value & Difference & p Value \\
\hline $\begin{array}{l}\text { Seattle angina score } \\
\text { BDI } \\
\text { GHQ } \\
\text { ADAM }(/ 10)\end{array}$ & $\begin{array}{l}42(14) \\
7(6.7) \\
10(5.9) \\
6(2.4)\end{array}$ & $\begin{array}{l}45(16.6) \\
7(4.8) \\
12(3.7) \\
6(2.2)\end{array}$ & $\begin{array}{l}0.35 \\
0.83 \\
0.3 \\
0.5\end{array}$ & $\begin{array}{l}44(13.8) \\
9(6) \\
12(4.1) \\
7(2.0)\end{array}$ & $\begin{array}{l}40(11.1) \\
4(4.2) \\
8.6(2.5) \\
4(2.3)\end{array}$ & $\begin{array}{l}0.075 \\
0.012^{*} \\
0.017^{*} \\
0.007^{\star}\end{array}$ & $\begin{array}{l}-3.7(5.9) \\
-4.8(6.1) \\
-3.1(2.9) \\
-3.1(3.3)\end{array}$ & $\begin{array}{l}0.14 \\
0.007^{*} \\
0.075 \\
0.015^{\star}\end{array}$ \\
\hline
\end{tabular}

${ }^{*} \mathrm{p}<0.05$

ADAM, androgen deficiency in the adult male screen score; BDI, Beck depression inventory; $G H Q$, general health screen questionnaire. 


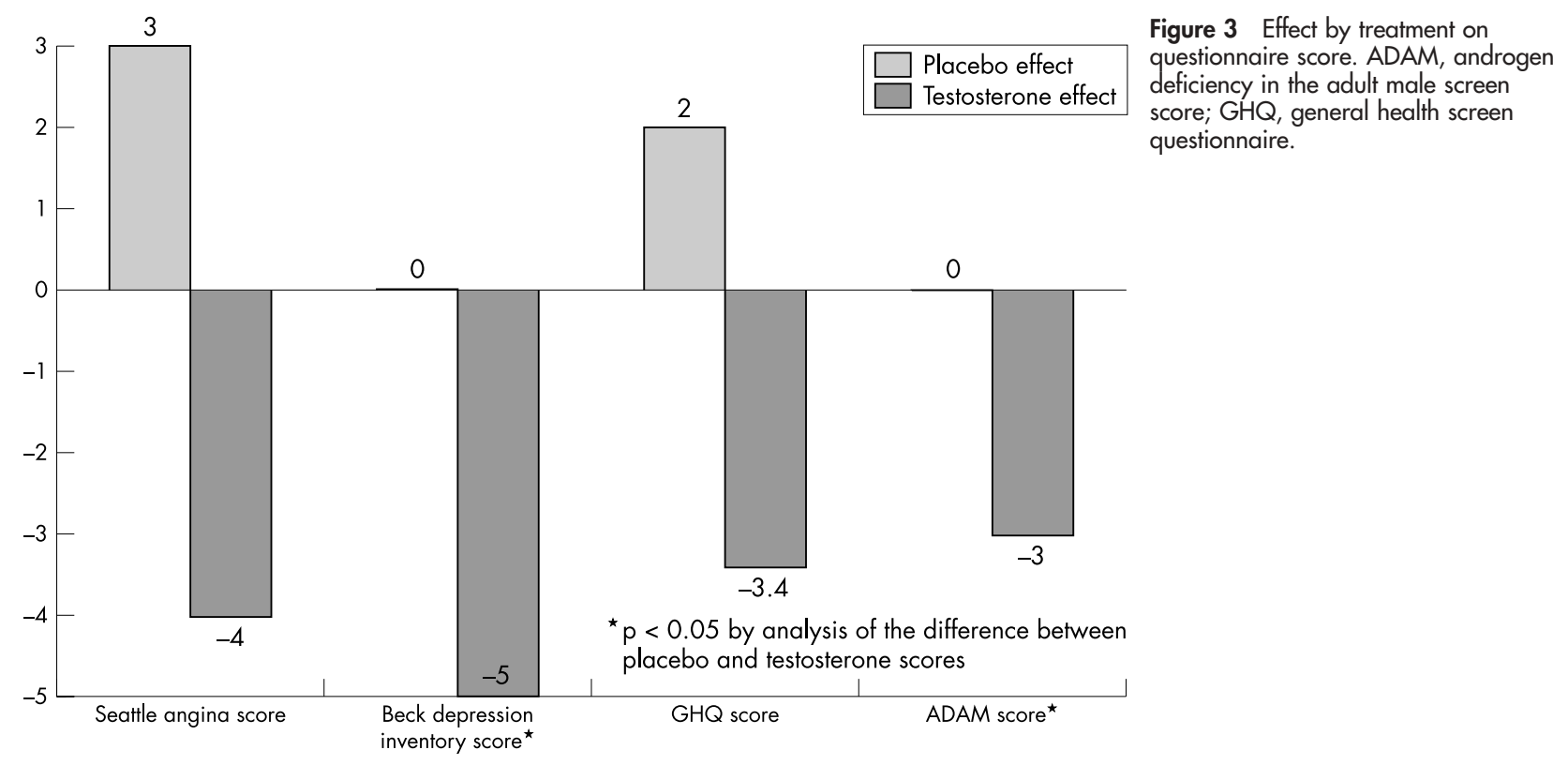

reduced by hormone replacement. ${ }^{40}$ In castrated or sham castrated mice subjected to trauma haemorrhage, the macrophages from castrated animals produced more interleukin 1 and interleukin 6 than those from controls. ${ }^{41}$ There have been very few human studies, but elderly men with hypogonadism induced by gonadotrophin releasing hormone agonists developed a significant increase in serum TNF $\alpha$ and interleukin 6 compared with baseline. ${ }^{42}$ Hormone replacement in this group did reduce cytokine concentrations but failed to reach acceptable levels of significance. Yesilova and

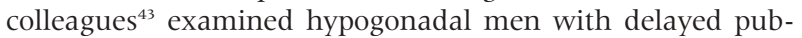
erty and found increased levels of immune activation that were reversed with androgen stimulating therapy. The present study therefore adds to the accumulating evidence that testosterone may have a beneficial anti-inflammatory action.

\section{Limitations}

The patients in this study did not present with symptoms of androgen deficiency; they were found to be hypogonadal during a cross sectional observational study. ${ }^{9}$ There may be a considerable number of men for whom testosterone therapy may be indicated, since men with coronary heart disease have lower testosterone concentrations than men with normal coronary angiograms and nearly a quarter of men with coronary disease are biochemically androgen deficient. Although a positive effect on inducible myocardial ischaemia was recorded we could not confirm a beneficial effect on the symptom of angina. An improvement in the Seattle angina questionnaire only approached significance and patients were not required to complete symptom diaries. Furthermore, the protocol precluded an analysis of angina threshold, since treadmill tests were terminated at the onset of $1 \mathrm{~mm} \mathrm{ST}$ segment depression. Although the study was single blind in design, ECG data were recorded with the Marquette 002E software package effectively eliminating observer bias.

\section{Conclusions}

This study gives further supportive evidence of the antiischaemic and anti-inflammatory effect of testosterone. In the past 30 years, at least six studies of various design have reported the effects of androgen therapy on coronary ischaemia ${ }^{14-16} 44-46$; all but one have reported a beneficial effect. ${ }^{46}$ The present study of exclusively hypogonadal men found the improvement in time to ischaemic threshold to be greater than that among the randomly selected men reported by English and colleagues, ${ }^{16}$ using identical assessment. Furthermore, the effects in the present study were seen in the presence of concomitant antianginal medications, whereas in some earlier studies angina medications were withdrawn. Major improvements in mood were reported by all patients and hypogonadal symptoms were abolished in three. The dose of testosterone used in the study may have been inadequate for some of our patients and uptitration of dose may be required to abolish hypogonadal symptoms in the remainder. Finally, potentially beneficial reductions in total cholesterol and reductions of $\mathrm{TNF} \alpha$ were seen on testosterone treatment. There were no serious adverse effects other than a small rise in PSA, which was expected in this hypogonadal cohort. The overall level of patient satisfaction was high. Despite the limitations discussed above, this study suggests that the cautionary advice of the British National Formulary on androgen therapy may be unwarranted. Testosterone therapy offers clinical benefit to this patient group.

\section{ACKNOWLEDGEMENTS}

The authors acknowledge Miss Joanne Hall for her expert assistance with hormone ELISAs. Thanks also to Mrs Judith Edwards, Miss Lucy Gomersall, and Mrs Carole Evans for their assistance with patients during treadmill exercise testing and expertise with the Marquette 002E software package.

CJM recruited all the subjects, supervised assessment, performed statistical analysis, and wrote the paper. KK performed cytokine ELISAs; PJP and PDM helped to design the protocol and prepared the ethics submission; THJ, RDJ, and KSC evolved the concept, designed the protocol, and edited the manuscript; KSC obtained funding for the study; the guarantors of the paper are KSC and THJ.

\section{Authors' affiliations}

C J Malkin, P J Pugh, P D Morris, K S Channer, Department of Cardiology, Royal Hallamshire Hospital, Sheffield S10 2JF, UK

K E Kerry, R D Jones, T Hugh Jones*, Academic Unit of Endocrinology, Hormone and Vascular Biology Group, Division of Genomic Medicine, University of Sheffield, Sheffield, UK

*Also the Centre for Diabetes \& Endocrinology, Barnsley District General Hospital, Barnsley, UK

There is no conflict of interest 


\section{REFERENCES}

1 Wingard DL, Suarez L, Barrett-Connor E. The sex differential in mortality from all causes and ischemic heart disease. Am J Epidemiol 1983;1 17:165-72.

2 Jousilahti $\mathbf{P}$, Vartiainen E, Tuomilehto J, et al. Sex, age, cardiovascular risk factors, and coronary heart disease: a prospective follow-up study of 14786 middle-aged men and women in Finland. Circulation 1999;99:1165-72.

3 Rossouw JE, Anderson GL, Prentice RL, et al. Risks and benefits of estrogen plus progestin in healthy postmenopausal women: principal results from the women's health initiative randomized controlled trial. JAMA 2002;288:321-33.

4 Hulley S, Grady D, Bush T, et al. Randomized trial of estrogen plus progestin for secondary prevention of coronary heart disease in postmenopausal women. Heart and estrogen/progestin replacement study (HERS) research group. JAMA 1998;280:605-13.

5 Simon D, Charles MA, Nahoul K, et al. Association between plasma total testosterone and cardiovascular risk factors in healthy adult men: The telecom study. J Clin Endocrinol Metab 1997;82:682-5.

$6 \mathrm{Hak} \mathrm{AE}$, Witteman JC, de Jong $\mathrm{FH}$, et al. Low levels of endogenous androgens increase the risk of atherosclerosis in elderly men: the Rotterdam study. J Clin Endocrinol Metab 2002;87:3632-9.

7 Van den Beld AW, Bots ML, Janssen JA, et al. Endogenous hormones and carotid atherosclerosis in elderly men. Am J Epidemiol 2003;157:25-31.

8 English KM, Mandour O, Steeds RP, et al. Men with coronary artery disease have lower levels of androgens than men with normal coronary angiograms. Eur Heart J 2000;21:890-4.

9 Pugh PJ, Malkin CJ, Morris PD, et al. Prevalence of hypogonadism in men with coronary artery disease. J Am Coll Cardiol 2003;41:344.

10 Vermeulen A, Kaufman JM. Ageing of the hypothalamo-pituitary-testicular axis in men. Horm Res 1995;43:25-8.

11 Yue $\mathbf{P}$, Chatteriee $\mathrm{K}$, Beale $\mathrm{C}$, et al. Testosterone relaxes rabbit coronary arteries and aorta. Circulation 1995:91:1154-60.

12 Jones RD, Pugh PJ, Jones TH, et al. The vasodilatory action of testosterone: a potassium-channel opening or a calcium antagonistic action? Br J Pharmacol 2003; 138:733-44.

13 Webb CM, McNeill JG, Hayward CS, et al. Effects of testosterone on coronary vasomotor regulation in men with coronary heart disease. Circulation 1999; 100:1690-6.

14 Jaffe MD. Effect of testosterone cypionate on postexercise ST segmen depression. Br Heart J 1977;39:1217-22.

15 Rosano GM, Leonardo F, Pagnotta P, et al. Acute anti-ischemic effect of testosterone in men with coronary artery disease. Circulation 1999;99:1666-70.

16 English KM, Steeds RP, Jones TH, et al. Low-dose transdermal testosterone therapy improves angina threshold in men with chronic stable angina: a randomized, double-blind, placebo-controlled study. Circulation 2000;102:1906-11.

17 Tremblay RR, Dube JY. Plasma concentrations of free and non-TeBG bound testosterone in women on oral contraceptives. Contraception 1974: 10:599-605.

18 Berg G, Schreier L, Geloso G, et al. Impact on lipoprotein profile after longterm testosterone replacement in hypogonadal men. Horm Metab Res 2002;34:87-92

19 Kouri EM, Pope HG Jr, Oliva PS. Changes in lipoprotein-lipid levels in normal men following administration of increasing doses of testosterone cypionate. Clin J Sport Med 1996;6:152-7.

20 Tenover JS. Effects of testosterone supplementation in the aging male. J Clin Endocrinol Metab 1992;75:1092-8.

21 Sorva R, Kuusi T, Taskinen MR, et al. Testosterone substitution increases the activity of lipoprotein lipase and hepatic lipase in hypogonadal males Atherosclerosis 1988;69:191-7.

22 Zgliczynski S, Ossowski M, Slowinska-Srzednicka J, et al. Effect of testosterone replacement therapy on lipids and lipoproteins in hypogonadal and elderly men. Atherosclerosis 1996;121:35-43.

23 Tripathy D, Shah P, Lakshmy R, et al. Effect of testosterone replacement on whole body glucose utilisation and other cardiovascular risk factors in males with idiopathic hypogonadotrophic hypogonadism. Horm Metab Res 1998; 30:642-5.

24 Uyanik BS, Ari Z, Gumus B, et al. Beneficial effects of testosterone undecanoate on the lipoprotein profiles in healthy elderly men: a placebo controlled study. Jpn Heart J 1997;38:73-82.
25 Whitsel EA Boyko EJ Matsumoto AM et al. Intramuscular testosterone esters and plasma lipids in hypogonadal men: a meta-analysis. Am J Med 2001;111:261-9.

26 Marin P, Krotkiewski M, Bjorntorp P. Androgen treatment of middle-aged, obese men: effects on metabolism, muscle and adipose tissues. Eur J Med 1992;1:329-36.

27 Simon D, Charles MA, Lahlou N, et al. Androgen therapy improves insulin sensitivity and decreases leptin level in healthy adult men with low plasma total testosterone: a 3-month randomized placebo-controlled trial. Diabetes Care $2001 ; 24: 149-51$

28 Malkin CJ, Pugh PJ, Jones TH, et al. Testosterone for secondary prevention in men with ischaemic heart disease? Q J M 2003;96:521-9.

29 Fak AS, Erenus $M$, Tezcan $\mathrm{H}$, et al. Effects of simvastatin only or in combination with continuous combined hormone replacement therapy on serum lipid levels in hypercholesterolaemic post-menopausal women. Eur Heart J 2000;21:190-7.

30 Sbarouni E, Kyriakides ZS, Kremastinos D. The effect of hormone replacement therapy alone and in combination with simvastatin on plasma lipids of hypercholesterolemic postmenopausal women with coronary artery disease. $J$ Am Coll Cardiol 1998;32:1244-50

31 Ridker PM, Rifai N, Pfeffer M et al. Elevation of tumor necrosis factor-alpha and increased risk of recurrent coronary events after myocardial infarction. Circulation 2000; 101:2149-53.

32 Cutolo M, Wilder RL. Different roles for androgens and estrogens in the susceptibility to autoimmune rheumatic diseases. Rheum Dis Clin North Am 2000;26:825-39.

33 Cutolo $M$, Balleari E, Giusti $M$, et al. Androgen replacement therapy in male patients with rheumatoid arthritis. Arthritis Rheum 1991;34:1-5.

34 Bizzarro A, Valentini G, Di Martino G, et al. Influence of testosterone therapy on clinical and immunological features of autoimmune diseases associated with Klinefelter's syndrome. J Clin Endocrinol Metab 1987;64:32-6

35 Olsen NJ, Kovacs WJ. Case report: testosterone treatment of systemic lupus erythematosus in a patient with Klinefelter's syndrome. Am J Med Sci 1995; 310:158-60

36 Hatakeyama H, Nishizawa M, Nakagawa A, et al. Testosterone inhibits fumor necrosis factor-alpha-induced vascular cell adhesion molecule-1 expression in human aortic endothelial cells. FEBS Lett 2002;530:129-32

37 D'Agostino P, Milano S, Barbera C, et al. Sex hormones modulate inflammatory mediators produced by macrophages. Ann N Y Acad Sci 1999:876:426-9.

38 Gornstein RA, Lapp CA, Bustos-Valdes SM, et al. Androgens modulate interleukin-6 production by gingival fibroblasts in vitro. J Periodontol 1999;70:604-9.

39 Parkar M, Tabona P, Newman H, et al. IL-6 expression by oral fibroblasts is regulated by androgen. Cytokine 1998;10:613-9.

40 Spinedi E, Suescun MO, Hadid R, et al. Effects of gonadectomy and sex hormone therapy on the endotoxin-stimulated hypothalamo-pituitary-adrenal axis: evidence for a neuroendocrine-immunological sexual dimorphism. Endocrinology 1992;131:2430-6.

41 Wichmann MW, Ayala A, Chaudry IH. Male sex steroids are responsible for depressing macrophage immune function after trauma-hemorrhage. Am J Physiol 1997; 273:C1335-40.

42 Khosla S, Atkinson EJ, Dunstan CR, et al. Effect of estrogen versus testosterone on circulating osteoprotegerin and other cytokine levels in normal elderly men. J Clin Endocrinol Metab 2002;87:1550-4.

43 Yesilova Z, Ozata M, Kocar IH, et al. The effects of gonadotropin treatment on the immunological features of male patients with idiopathic hypogonadotropic hypogonadism. J Clin Endocrinol Metab 2000;85:66-70.

44 Wu SZ, Weng XZ. Therapeutic effects of an androgenic preparation on myocardial ischemia and cardiac function in 62 elderly male coronary heart disease patients. Chin Med J (Engl) 1993;106:415-8.

45 Webb CM, Adamson DL, de Zeigler D, et al. Effect of acute testosterone on myocardial ischemia in men with coronary artery disease. Am J Cardiol. 1999;83: 437-9, A9)

46 Thompson PD, Ahlberg AW, Moyna NM, et al. Effect of intravenous testosterone on myocardial ischemia in men with coronary artery disease. Am Heart J 2002; 143:249-56. 